\section{$\underset{\substack{\text { hommes } \\ \text { \& migrations }}}{ }$}

\section{Hommes \& migrations}

Revue française de référence sur les dynamiques

migratoires

$1306 \mid 2014$

Ecriture et migration

\title{
Ali a les yeux bleus
}

Film italien 2012 de Claudio Giovannesi

\section{Anaïs Vincent}

\section{Q OpenEdition \\ 1 Journals}

\section{Édition électronique}

URL : http://journals.openedition.org/hommesmigrations/2858

DOI : 10.4000/hommesmigrations.2858

ISSN : 2262-3353

\section{Éditeur}

Musée national de l'histoire de l'immigration

\section{Édition imprimée}

Date de publication : 1 avril 2014

Pagination : 158-160

ISBN : 978-2-919040-27-8

ISSN : $1142-852 X$

\section{Référence électronique}

Anaïs Vincent, «Ali a les yeux bleus », Hommes \& migrations [En ligne], 1306 | 2014, mis en ligne le 06 août 2014, consulté le 22 septembre 2020. URL : http://journals.openedition.org/hommesmigrations/ 2858 ; DOI : https://doi.org/10.4000/hommesmigrations.2858

Ce document a été généré automatiquement le 22 septembre 2020.

Tous droits réservés 


\title{
Ali a les yeux bleus
}

\author{
Film italien 2012 de Claudio Giovannesi
}

\section{Anaïs Vincent}

1 Les naufrages d'embarcations de fortune au large des côtes italiennes se sont multipliés ces derniers temps. Avec les conflits au Proche et du Moyen-Orient, l'Italie est devenue le théâtre quotidien de ces drames. Étape obligée de nombreux réfugiés, elle peine à accueillir ces flux de clandestins. Le ministre de l'Intérieur Angelino Alfano a récemment apostrophé les instances européennes à ce sujet et a menacé de laisser partir tous ces demandeurs d'asile, si elles ne venaient pas au secours de l'Italie. La question de l'immigration est sur toutes les lèvres en ce lendemain amer d'élections européennes.

2 Le héros du dernier film du réalisateur italien Claudio Giovannesi n'est pas un primoarrivant. Il fait partie de cette deuxième génération engluée dans une double culture schizophrénique. Il est, d'une part, pétri par l'éducation de ses parents de confession musulmane et, d'autre part, par celle de son pays marqué par le catholicisme.

Dans la continuité de son premier documentaire, le cinéaste scrute d'un œil bienveillant la jeunesse italienne issue des classes populaires. L'histoire d'amour de Nader, un des acteurs non professionnels de son précédent film - qui joue ici son propre rôle -, est à l'origine de cette fiction.

4 Ostie, banlieue balnéaire de Rome, des adolescents, Nader l'Égyptien d'Ostie, Stefano le Romain, Zoran le Roumain, font les quatre cents coups. Entre cambriolages et petits délits, le quotidien des trois garçons suit son cours. Mais tout bascule lorsque Nader annonce à sa famille sa relation avec Brigitte, une jeune Italienne. Sa mère s'oppose catégoriquement à cette union. Révolté, le jeune homme décide de quitter le cocon familial. Pendant une semaine, on suit l'adolescent tiraillé entre ces deux cultures.

5 Le titre du film est emprunté à un poème de 1962 du sulfureux Pier Paolo Pasolini. Dans une prose prophétique, le cinéaste y parle des rapports Nord/Sud et de la transformation de la société italienne par l'immigration. Ce multi-culturalisme est une réalité aujourd'hui. Sur la péninsule, l'immigration représente actuellement pas moins de $10 \%$ de la population, alors que le taux de natalité reste faible. Le film se déroule à Ostie et ce n'est pas un hasard. C'est une banlieue multi-ethnique de Rome et c'est sur 
une plage d'Ostie qu'en 1975 a été retrouvé le corps sans vie de Pier Paolo Pasolini. Nader porte des lentilles bleues, un autre hommage au héros du poème du cinéaste défunt.

6 L'adolescent tente de s'européaniser. En échec scolaire, il ne parvient pas à se conformer à la société catholique. Ayant été lui-même élevé dans la religion musulmane, il rejette les symboles chrétiens. En cours, il prend à partie son professeur et l'interroge sur le bien-fondé de la présence d'un crucifix sur le mur de la salle de classe. La laïcité italienne est très particulière. La forte prégnance de la religion dans la société ne facilite pas l'intégration.

7 Dans une veine naturaliste, le cinéaste dresse un portrait sombre de la société italienne et dénonce l'échec d'une politique d'immigration qui ne parvient pas à insérer ses minorités. 